\title{
Analisis Image Comments to Image Likes Ratio Instagram Pada 5 Gamer Dengan Followers Terbanyak di Indonesia
}

\author{
I Kadek Wahyu Diatmika (19101233) \\ wahyudiatmika8@gmail.com
}

\begin{abstract}
Instagram (abbreviated as IG or Insta) is a photo and video sharing application that allows users to take photos, take videos, apply digital filters, and share them on various social networking services, including Instagram's own. Until the first quarter of 2021, the number of active Instagram users worldwide reached 1.07 billion and 354 million users aged 25 to 34 years. In Indonesia, there are more than 91.77 million active users of social media Instagram. The majority of users are women, which is $52.6 \%$. The rise of Instagram users in Indonesia is used by a number of Youtuber Gamers to promote their Youtube channel. The 5 gamers who take advantage of this are: Miaw Aug, Dyland Pros, Jess No Limit, Frost Diamond, and Kemas Pake $Z$. The purpose of this study is to calculate the credibility of the Instagram accounts of these 5 gamers. The method used for this research is quantitative exploratory method. The results of this study indicate that the Instagram account that shows the highest credibility is Frost Diamond which gets the first rank.
\end{abstract}

\begin{abstract}
ABSTRAK
Instagram (disingkat IG atau Insta) adalah sebuah aplikasi berbagi foto dan video yang memungkinkan pengguna mengambil foto, mengambil video, menerapkan filter digital, dan membagikannya ke berbagai layanan jejaring sosial, termasuk milik Instagram sendiri. Hingga kuartal I-2021, jumlah pengguna aktif Instagram di seluruh dunia mencapai 1,07 miliar dan 354 juta penggunanya berusia 25 hingga 34 tahun (Rizaty 2021). Di Indonesia terdapat lebih dari 91,77 juta pengguna aktif sosial media Instagram dan mayoritas penggunanya adalah dari kaum perempuan yaitu sebesar 52,6\% (Rizaty 2021). Maraknya pengguna Instagram di Indonesia dimanfaatkan oleh sejumlah Youtuber Gamer untuk mempromosikan channel Youtube mereka. Adapun 5 gamer yang memanfaatkan hal tersebut adalah : Miaw Aug, Dyland Pros, Jess No Limit, Frost Diamond, dan Kemas Pake Z. Tujuan dari penelitian ini adalah untuk menghitung kredibilitas akun Instagram dari 5 gamer tersebut. Metode yang digunakan untuk penelitian ini adalah metode eksploratif kuantitatif. Hasil dari penelitian ini menunjukan bahwa akun Instagram yang menunjukan kredibilitas tertinggi adalah Frost Diamond yang mendapat peringkat pertama.
\end{abstract}

Keyword : Credibility Instagram Account; Social Media Promotion; Social Media Instagram; Image Comments to Image Likes Ratio; Gamer Indonesia. 


\section{PENDAHULUAN}

Teknologi informasi dan komunikasi yang berkembang sangat pesat mampu mempengaruhi masyarakat dalam menciptakan cara baru untuk berkomunikasi dan berinteraksi melalui media sosial. Lahirnya media sosial menyebabkan beberapa perubahan dalam diri masyarakat. Dari berbagai kalangan dan usia hampir semua masyarakat Indonesia memiliki dan menggunakan media sosial sebagai salah satu sarana untuk berkomunikasi dan berinteraksi. Hal ini tentu saja bermanfaat karena masyarakat dapat berinteraksi satu sama lain hanya dengan bermodalkam HP atau laptop.

Perkembangan teknologi informasi dan komunikasi yang sangat pesat juga memberikan dampak pada cara masyarakat untuk berkomunikasi. Pada awalnya masyarakat hanya bisa menggunakan media sosial tersebut untuk chattingan dan mengirim email. Namun seiring berkembangnya teknologi, sudah banyak media sosial yang bisa digunakan untuk alat komunikasi. Salah satu media sosial tersebut adalah Instagram. Instagram merupakan media sosial yang sangat banyak penggunanya. Pada aplikasi ini, pengguna bisa mengunggah foto dan video (yang saat ini durasinya sudah bisa melebihi 1 menit) serta dapat berkomunikasi dengan sesama pengguna Instagram lainnya.

Kemunculan media sosial Instagram ini dimanfaatkan oleh sejumlah orang sebagai sarana untuk mempromosikan dirinya. Salah satu contohnya adalah beberapa gamer yang sudah terkenal membuat akun instagram, kemudian merekan akan lebih dikenal oleh masyarakat luas. Cukup banyak gamer yang sudah memiliki akun instagram, namun mereka tidak hanya memposting sesuatu yang berhubungan dengan game, kadang-kadang mereka memposting kegiatannya sehai-hari yang tidak mereka tunjukan saat bermain game. Hal itu menyebabkan mereka mendapatkan banyak like dan comment dari berbagai pengguna instagram lainnya. Adapun 5 Gamer Dengan Followers Terbanyak di Indonesia, diantaranya yaitu : MiawAug, Dyland Pros, Jess No Limit, Frost Diamond, Kemas Pake Z (Hannahanisa 2019).

Penelitian ini menggunakan metode eksploratif kuantitatif, dan akan menghitung menggunakan rasio-rasio yang ada pada Instagram. Pada penelitian (Permana 2021) menjelaskan bahwa terdapat 8 rasio yang ada pada sosial media Instagram dan relevan digunakan sebagai media ukur kredibilitas akun yang ada. Penelitian ini hanya berfokus untuk menghitung kredibilitas Image Comments to Image Likes Ratio pada 5 Gamer Dengan Followers Terbanyak di Indonesia. Tujuan dari penelitian ini adalah mengetahui kredibilitas performa dari akun Instagram 5 Gamer Dengan Followers Terbanyak di Indonesia menggunakan Image Comments to Image Likes Ratio.

\section{TINJAUAN PUSTAKA}

Perkembangan teknologi saat ini berkembang sangat pesat, terutama pada teknologi komunikasi dan informasi. Masyarakat saat ini dibuat lebih mudah melakukan interaksi atau komunikasi tanpa berkontak fisik secara langsung. Contoh perkembangan teknologi komunikasi dan informasi adalah munculnya beberapa aplikasi yaitu WhatsApp, Instagram, 
TikTok, Twitter, Facebook, dan Youtube. Salah satu contoh teknologi yang akan diteliti kali ini adalah pada aplikasi media sosial yaitu Instagram. Pengguna dari aplikasi ini bukan hanya dari kalangan anak muda saja, mulai dari anak-anak sampai orang tuapun juga aktif menggunakan Instagram.

Saat pertama kali dirilis, aplikasi Instagram diunduh oleh sekitar 10.000 pengguna hanya dalam hitungan jam. Kemudian di tahun berikutnya, jumlah unduhan aplikasi Instagram dilaporkan mencapai hingga 10 juta kali (Stephanie, C. 2020). Namun, saat ini Instagram merupakan salah satu aplikasi yang memiliki banyak sekali pengguna aktif yaitu lebih dari 1 miliar pengguna. Aplikasi ini menawarkan banyak fitur, yaitu IG Story, Direct Message, IGTV, IG Music, Shop, Dark Mode, dan fitur baru yang sedang banyak digunakan sekarang yaitu Instagram Reels (Fitriani 2021). Menurut penelitian yang dilakukan peneliti, walaupun Instagram memiliki banyak fitur, namun fitur unggulan yang banyak digunakan penggunanya adalah IG Story. Di dalam IG Story, pengguna bisa memposting foto, video, musik, menggunakan stiker, menggunakan filter, dan masih banyak lagi.

Sesuai dengan penelitian yang dilakukan oleh peneliti, selain digunakan sebagai media untuk berkomunikasi dan menyebarkan informasi, Instagram juga kerap digunakan sebagai media promosi. Salah satu contohnya adalah para gamers yang mengunggah kontennya di Youtube mempromosikannya lagi lewat media sosial Instagram. Hal ini dilakukan agar kontennya tidak hanya dikenal dalam satu media saja, namun juga dikenal di berbagai media.

Instagram dirasakan memiliki kekuatan ataupun pengaruh dalam media promosi, sehingga menimbulkan kualitas akun yang menentukan strata maupun kredibilitas pemilik akun. Kredibilitas akun Instagram merupakan suatu hal yang cukup penting untuk berbagai kepentingan. Kredibilitas sebuah akun Instagram dapat diukur dari tingkat performa yang dihasilkan secara matematis. Dalam mengukur performa diperlukan skala pengukuran yang tertuang ke dalam rasio (Permana 2021).

\section{METODE PENELITIAN}

Penelitian ini menggunakan metode eksploratif kuantitatif untuk mengetahui kredibilitas dari performa akun Instagram 5 Gamers Dengan Followers Terbanyak di Indonesia. Metode eksploratif merupakan suatu jenis penelitian yang memiliki tujuan untuk melakukan eksplorasi atau memperdalam pengetahuan ataupun mencari ide-ide baru mengenai suatu hal tertentu, guna merumuskan permasalahan dengan secara lebih terperinci ataupun mengembangkan hipotesis dan bukanlah untuk menguji hipotesis.

Tujuan dari penelitian ini yaitu mengetahui nilai kredibillitas dari performa akun Instagram 5 Gamers Dengan Followers Terbanyak di Indonesia. Ada beberapa tahapan - tahapan yang harus dilakukan dalam penelitian ini, sehingga mampu menemukan peringkat pertama akun Instagram 5 Gamers Dengan Followers Terbanyak di Indonesia yang memiliki performa terbaik. Langkah-langkah yang dilakukan pada penelitian ini, diantaranya yaitu : 


\section{Melakukan Eksplorasi Pada Website Untuk Menentukan Objek yang Akan Dianalisa.}

Eksplorasi ini dilakukan pada halaman website yang menyediakan informasi mengenai objek yang akan di teliti. Setelah ekslorasi selesai dilakukan, maka akan ditemukan nama-nama gamers di Indonesia yang akan dijadikan objek analisa. Setelah melakukan eksplorasi pada halaman website, maka langkah selanjutnya yaitu mencari nama akun Instagram dari masing-masing gamers tersebut. Pastikan semua gamers memiliki akun pada aplikasi sosial media Instagram.

\section{Menghitung Nilai Rata-Rata Variable Dari 5 Gamers Dengan Followers Terbanyak di Indonesia.}

Pada langkah ini, peneliti menghitung nilai variable image comments dan variable image likes. Variabel merupakan suatu besaran yang dapat diubah atau berubah sehingga dapat mempengaruhi peristiwa atau hasil penelitian. Untuk menghitung nilai rata-rata dari variabel image comments dan variabel image likes yaitu dengan cara mengambil minimal 10 postingan kemudian dihitung sehingga menemukan nilai ratarata dari masing-masing variabel.

\section{Menghitung Nilai Kredibilitas Rasio}

Untuk menghitung nilai kredibilitas dari image comments to image likes ratio, peneliti menggunakan cara membagi nilai variabel pertama dengan nilai variabel kedua. Jika image comments memiliki nilai 200 dan image likes memiliki nilai 800, maka cara menghitungnya yaitu $200: 800=0,25$. Dengan begitu nilai dari image comments to image likes ratio adalah 0,25 .

\section{Menentukan Peringkat Pada Akun TikTok}

Pada langkah terakhir yang dilakukan pada penelitian ini yaitu menentukan peringkat pada masing-masing rasio yang ada. Pada penentuan peringkat perlu melihat karakteristik dari rasio yang di teliti. Jika karakteristik rasio merupakan rendah, maka objek yang memiliki nilai rasio terendah akan mendapatkan angka 5 dan objek yang memiliki nilai rasio tertinggi akan mendapatkan angka 1. Namun jika rasio memiliki karakteritik tinggi maka objek yang mendapatkan nilai rasio tinggi akan mendapatkan angka 5 dan objek yang mendapatkan nilai rasio terendah akan mendapatkan angka 1 . Setelah mendapatkan hasil kredibilitas ratio maka dapat disimpulkan objek yang mana mendapatkan peringkat 1 sampai dengan peringkat 5 . 


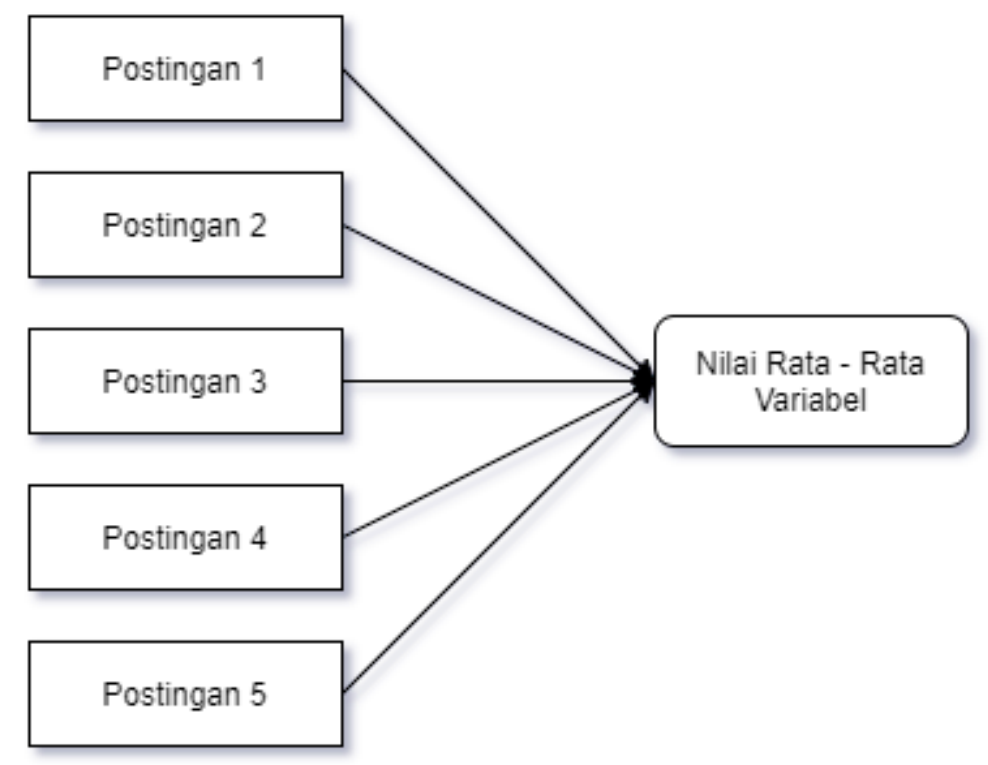

Gambar 1. Analisa Nilai Rata - Rata Variabel

\section{HASIL DAN PEMBAHASAN}

Akun Instagram dari 5 gamer dengan followers terbanyak di Indonesia, diantaranya :

\section{Miaw Aug}
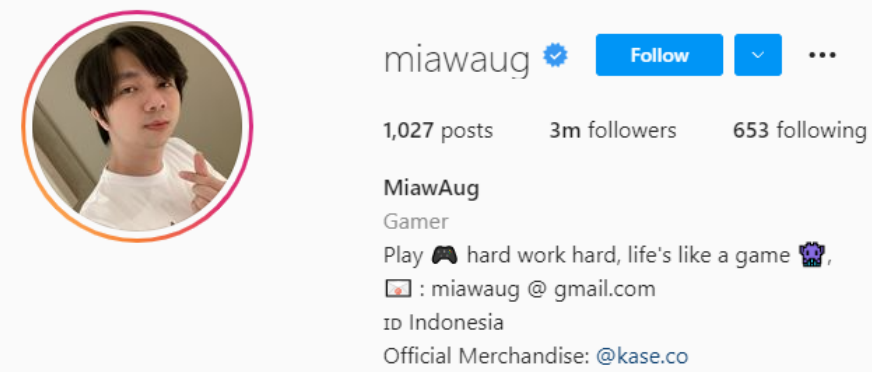

Gambar 2. Akun Instagram Miaw Aug

Sumber : https://www.instagram.com/miawaug/ (akses pada 19 Oktober 2021)

\section{Dyland Pros}
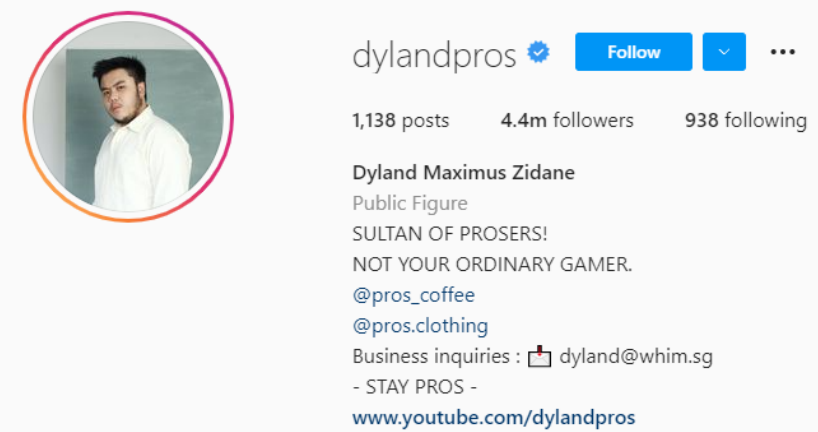

Gambar 3. Akun Instagram Dyland Pros

Sumber : https://www.instagram.com/dylandpros/ (akses pada 19 Oktober 2021) 


\section{Jess No Limit}
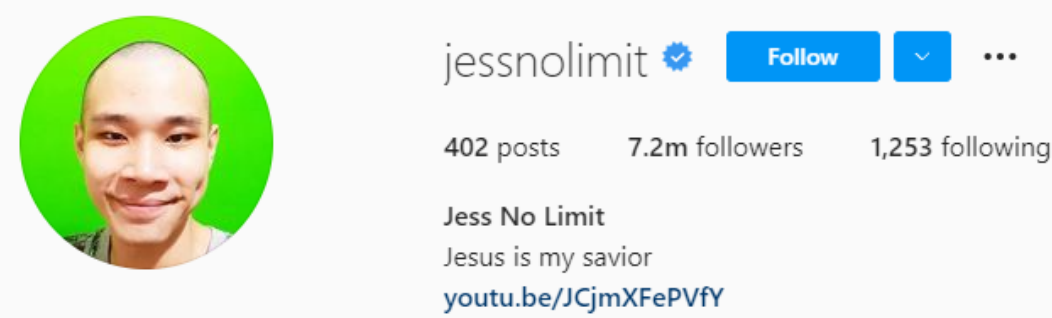

Gambar 4. Akun Instagram Jess No Limit

Sumber : https://www.instagram.com/jessnolimit/ (akses pada 19 Oktober 2021)

\section{Frost Diamond}

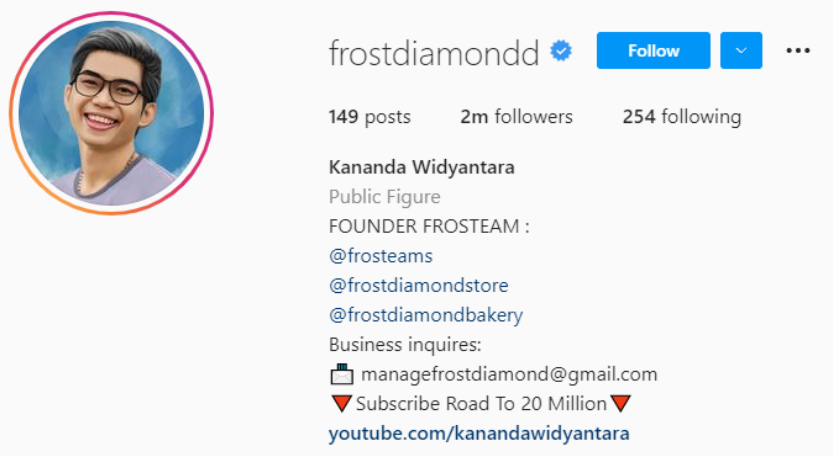

Gambar 5. Akun Instagram Frost Diamond

Sumber : https://www.instagram.com/frostdiamondd/ (akses pada 19 Oktober 2021)

\section{Kemas Pake $Z$}

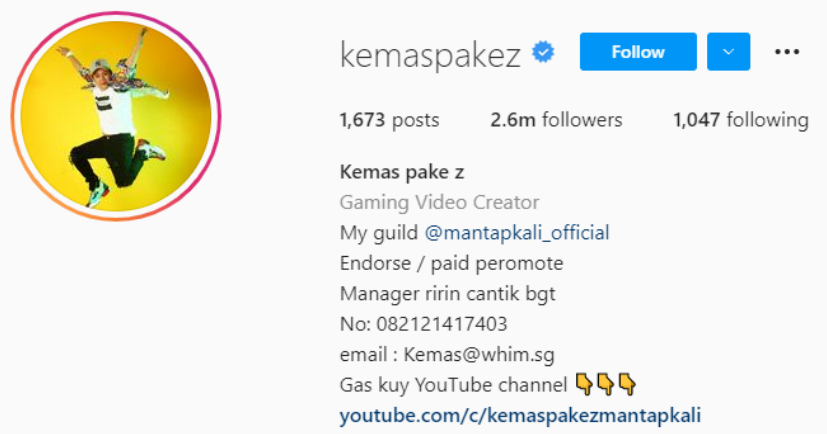

Gambar 6. Akun Instagram Kemas Pake Z

Sumber : https://www.instagram.com/kemaspakez/ (akses pada 19 Oktober 2021)

Dari kelima akun Instagram 5 Gamer dengan followers terbanyak di Indonesia, peneliti menemukan nilai dari masing-masing variabel yang ada untuk menghitung rasio Image Comments to Image Likes dari setiap akun. Pada akun Instagram terdapat 6 variabel, diantaranya yaitu :

1. Image Likes

2. Image Comments

3. Followers

4. Following

5. Video Views 

6. Video Comments
7. Video Likes
8. Posts

Dari kedelapan variabel yang disebutkan diatas, peneliti hanya fokus untuk menemukan hasil dari 2 variabel, yaitu :

1. Image Comments

2. Image Likes

Dari kedua variabel tersebut, kemudian peneliti menganalisa sehingga menemukan nilai ratarata dari variabel image comments dan variabel image likes. Untuk menghitung nilai rata-rata dari variabel image comments dan variabel image likes yaitu dengan cara mengambil minimal 10 postingan, kemudian dihitung sehingga menemukan nilai rata-rata dari masing-masing variabel. Berikut merupakan tabel nilai rata-rata dari masing-masing gamer dengan followers terbanyak di Indonesia, yaitu :

Tabel 1. Analisa Nilai Rata-Rata Variabel Image Comments dan Image Likes Akun Instagram Miaw Aug

\begin{tabular}{|c|c|c|}
\hline No. & Image Comments & Image Likes \\
\hline 1 & 316 & 62.642 \\
\hline 2 & 1.163 & 153.649 \\
\hline 3 & 10.099 & 79.180 \\
\hline 4 & 354 & 55.602 \\
\hline 5 & 983 & 125.641 \\
\hline 6 & 4.827 & 131.332 \\
\hline 7 & 212 & 31.702 \\
\hline 8 & 722 & 107.614 \\
\hline 9 & 477 & 58.295 \\
\hline 10 & 2.067 & 172.980 \\
\hline Total & 2.122 & $97.863,7$ \\
\hline
\end{tabular}

Sumber : Pengolah Data Excel 
Tabel 2. Analisa Nilai Rata-Rata Variabel Image Comments dan Image Likes Akun Instagram Dyland Pros

\begin{tabular}{|c|c|c|}
\hline No. & Image Comments & Image Likes \\
\hline 1 & 202 & 46.574 \\
\hline 2 & 293 & 12.899 \\
\hline 3 & 102 & 14.923 \\
\hline 4 & 519 & 41.896 \\
\hline 5 & 313 & 20.625 \\
\hline 6 & 931 & 48.750 \\
\hline 7 & 290 & 22.095 \\
\hline 8 & 6.197 & 62.378 \\
\hline 9 & 261 & 24.260 \\
\hline 0 & 1.670 & 96.361 \\
\hline Total & $1.077,8$ & $39.076,1$ \\
\hline
\end{tabular}

Sumber : Pengolah Data Excel

Tabel 3. Analisa Nilai Rata-Rata Variabel Image Comments dan Image Likes Akun Instagram Jess No Limit

\begin{tabular}{|c|c|c|}
\hline No. & Image Comments & Image Likes \\
\hline 1 & 1.507 & 150.989 \\
\hline 2 & 1.940 & 84.732 \\
\hline 3 & 2.771 & 329.671 \\
\hline 4 & 6.387 & 485.906 \\
\hline 5 & 3.254 & 338.323 \\
\hline 6 & 569 & 35.278 \\
\hline 7 & 459 & 34.018 \\
\hline 8 & 408 & 31.295 \\
\hline 9 & 2.499 & 424.930 \\
\hline 10 & 1.988 & 320.870 \\
\hline Total & $2.178,2$ & $223.601,2$ \\
\hline
\end{tabular}

Sumber : Pengolah Data Excel 
Tabel 4. Analisa Nilai Rata-Rata Variabel Image Comments dan Image Likes Akun Instagram Frost Diamond

\begin{tabular}{|c|c|c|}
\hline No. & Image Comments & Image Likes \\
\hline 1 & 2.596 & 28.269 \\
\hline 2 & 10.775 & 87.311 \\
\hline 3 & 5.584 & 80.933 \\
\hline 4 & 2.687 & 57.286 \\
\hline 5 & 3.188 & 69.187 \\
\hline 6 & 3.354 & 119.297 \\
\hline 7 & 1.765 & 102.389 \\
\hline 8 & 2.029 & 89.433 \\
\hline 9 & 2.212 & 90.571 \\
\hline 10 & 2.300 & 96.805 \\
\hline Total & 3.649 & $82.148,1$ \\
\hline
\end{tabular}

Sumber : Pengolah Data Excel

Tabel 5. Analisa Nilai Rata-Rata Variabel Image Comments dan Image Likes Akun Instagram Kemas Pake Z

\begin{tabular}{|c|c|c|}
\hline No. & Image Comments & Image Likes \\
\hline 1 & 135 & 27.500 \\
\hline 2 & 262 & 23.860 \\
\hline 3 & 442 & 32.161 \\
\hline 4 & 733 & 58.548 \\
\hline 5 & 3.164 & 122.766 \\
\hline 6 & 582 & 54.103 \\
\hline 7 & 770 & 58.678 \\
\hline 8 & 157 & 19.827 \\
\hline 9 & 277 & 39.929 \\
\hline 10 & 180 & 11.094 \\
\hline Total & 670,2 & $44.846,6$ \\
\hline
\end{tabular}

Sumber : Pengolah Data Excel

Setelah menghitung nilai rata-rata dari kelima akun tersebut, maka ditemukanlah nilai akhir dari variabel image comments dan image likes yaitu sebagai berikut. 
Tabel 6. Nilai Variabel Pada Akun Instagram 5 Gamer Dengan Followers Terbanyak di Indonesia

\begin{tabular}{|c|c|c|c|c|c|}
\hline Variable & Miaw Aug & Dyland Pros & Jess No Limit & Frost Diamond & Kemas Pake Z \\
\hline $\begin{array}{c}\text { Image } \\
\text { Comments }\end{array}$ & 2.122 & $1.077,8$ & $2.178,2$ & 3.649 & 670,2 \\
\hline $\begin{array}{c}\text { Image } \\
\text { Likes }\end{array}$ & $97.863,7$ & $39.076,1$ & $223.601,2$ & $82.148,1$ & $44.846,6$ \\
\hline
\end{tabular}

Sumber : Pengolah Data Excel

Pada penelitian kali ini peneliti berfokus untuk menghitung Image Comments to Image Likes Ratio. Untuk menghitung kredibilitas dari masing-masing akun Instagram, peneliti menghitung dengan cara membagi variabel 1 dengan variabel 2 , sehingga akan didapat hasil analisa rasio sebagai berikut.

Tabel 7. Hasil Perhitungan Rasio Akun Instagram

\begin{tabular}{|c|c|c|c|c|c|c|}
\hline No. & Ratio & Miaw Aug & $\begin{array}{c}\text { Dyland } \\
\text { Pros }\end{array}$ & Jess No Limit & $\begin{array}{c}\text { Frost } \\
\text { Diamond }\end{array}$ & $\begin{array}{c}\text { Kemas Pake } \\
\mathbf{Z}\end{array}$ \\
\hline 1 & $\begin{array}{c}\text { Image Comments } \\
\text { to Image Likes } \\
\text { Ratio }\end{array}$ & 0,02168322 & 0,027582077 & 0,00974145 & 0,044419774 & 0,014944277 \\
\hline
\end{tabular}

Sumber : Pengolah Data Excel

Image Comments to Image Likes Ratio memiliki karakteristik yang tinggi, artinya semakin tinggi nilai yang dihasilkan maka semakin baik kredibilitas dari akun tersebut. Untuk memberikan peringkat pada masing-masing Gamer Dengan Followers Terbanyak di Indonesia, peneliti memberikan angka 5 kepada gamer yang mendapatkan nilai tertinggi dan angka 1 untuk gamer yang mendapatkan nilai terendah. Berikut merupakan tabel urutan nilai yang dihasilkan oleh masing-masing gamer.

Tabel 8. Nilai Rasio Akun Instagram 5 Gamer Dengan Followers Terbanyak di Indonesia

\begin{tabular}{|c|c|c|c|c|c|}
\hline \multirow{2}{*}{ Ratio } & \multicolumn{5}{|c|}{ Nilai } \\
\cline { 2 - 6 } & $\begin{array}{c}\text { Miaw } \\
\text { Aug }\end{array}$ & $\begin{array}{c}\text { Dyland } \\
\text { Pros }\end{array}$ & $\begin{array}{c}\text { Jess No } \\
\text { Limit }\end{array}$ & $\begin{array}{c}\text { Frost } \\
\text { Diamond }\end{array}$ & $\begin{array}{c}\text { Kemas Pake } \\
\text { Z }\end{array}$ \\
\hline $\begin{array}{c}\text { Image } \\
\text { Comments to } \\
\begin{array}{c}\text { Image Likes } \\
\text { Ratio }\end{array}\end{array}$ & 3 & 4 & 1 & 5 & 2 \\
\hline
\end{tabular}

Sumber : Pengolah Data Excel

Dari Tabel Nilai Rasio Akun Instagram 5 Gamer Dengan Followers Terbanyak di Indonesia, dapat disimpulkan bahwa akun instagram Frost Diamond mendapatkan nilai rasio tertinggi untuk Image Comments to Image Likes Ratio. Sedangkan akun instagram Jess No Limit mendapatkan nilai terendah untuk rasio ini. Jadi, pada penelitian ini, akun instagram Frost 
Diamond memiliki kredibilitas performa yang lebih baik dibandingkan akun instagram yang lainnya.

\section{KESIMPULAN}

Tujuan dari penelitian ini adalah mengetahui kredibilitas performa dari akun Instagram 5 Gamer Dengan Followers Terbanyak di Indonesia menggunakan Image Comments to Image Likes Ratio. 5 Gamer tersebut diantaranya : Miaw Aug, Dyland Pros, Jess No Limit, Frost Diamond, dan Kemas Pake Z. Dari kelima gamer tersebut dapat disimpulkan bahwa :

1. Peringkat pertama diraih oleh Frost Diamond dengan nilai tertinggi yaitu 0,044419774

2. Peringkat kedua diraih oleh Dyland Pros dengan nilai 0,027582077

3. Peringkat ketiga diraih oleh Miaw Aug dengan nilai 0,02168322

4. Peringkat keempat diraih oleh Kemas Pake Z dengan nilai 0,014944277

5. Peringkat kelima diraih oleh Jess No Limit dengan nilai terendah yaitu 0,00974145 


\section{DAFTAR PUSTAKA}

Fitriani, Feni. 2021. "8 Fitur Instagram Terbaru 2021 Yang Perlu Kamu Tahu - Teknologi Bisnis.Com.” June 17, 2021.

https://teknologi.bisnis.com/read/20210617/280/1406682/8-fitur-instagram-terbaru2021-yang-perlu-kamu-tahu.

Hannahanisa. 2019. “10 Youtuber Gamers Indonesia Followers Terbanyak Pada Tahun 2019 | by Hannahanisa | Medium.” December 14, 2019.

https://medium.com/@hannahanisa97/10-youtuber-gamers-indonesia-followersterbanyak-pada-tahun-2019-77f81566d732.

Permana, Hendika. 2021. "Analisis Rasio Pada Instagram Untuk Penelitian Kualitatif Menggunakan Metode Ekploratif.” Jurnal Sistem Informasi Dan Komputer Terapan Indonesia (JSIKTI) 3 (3): 44-56. https://doi.org/10.22146/jsikti.

Rizaty, Monavia. 2021. "Inilah Negara Pengguna Instagram Terbanyak, Indonesia Urutan Berapa? | Databoks.” August 3, 2021.

https://databoks.katadata.co.id/datapublish/2021/08/03/inilah-negara-penggunainstagram-terbanyak-indonesia-urutan-berapa. 